\title{
Paternidade e saúde reprodutiva: discursos de jovens em documentários autobiográficos
}

Geraldo Pereira Junior*, Vera H elena Ferraz de Siqueira**, Luiz Augusto Rezende**

Resumo: Esteartigo apresentaum estudo empírico, fundamentado em noções pós-estruturalistas, voltado à identificação designificad os atribuídos por al guns jovens à temática "paternidade", em relação, principalmente, a aspectos de saúde reprodutiva e sexualidade. 0 sdados foram geradosa partir da realização, pelos jovens, dedocumentáriosautobiográficos sobreessatemática. Evidenciou-se que os aspectos detransformação dos discursos sobre paternidade são muito sutis, dispersosem um número crescentedediscursosequeelesseapoiam tanto em paradigmas tradicionaiscomo não tradicionais.

Palavras-chave: paternidades; sexualidade; gênero; identidades; documentáriosautobiográficos.

Paternity and reproductive health: youth discourses in auto biographical documentaries

Abstract: Thisarticlepresents an empirical study founded on post-structural notions, aiming at identifying the meanings attributed by some youngsters on the issue of paternity, mainly related to reproductive health and sexuality. $D$ ata was generated from autobiographical documentaries about theissue of paternity prepared by theyoungsters. It was evidenced that the transformational aspects of the discourses on paternity are very subtle, dispersed in an increasing number of discourses and relying both on the traditional and non-traditional paradigms.

Key words: paternity; sexuality; gender; identities; autobiographical documentaries.

\section{Introdução}

Recentemente, movimentos políticos e teóricos vêm discutindo a paternidade, que passa a ser problematizada a partir de várias perspectivas, incluindo a da

* Mestre pelo N úcleo de Tecnologia Educacional em Saúde da Universidade Federal do Rio de Janeiro (N utes-UFRJ), trabalha com formação audiovisual de jovens e de professores. Rio de Janeiro, RJ, Brasil. pereira_acadêmico@yahoo.com.br

** Professora do Laboratório de Linguagense M ediações do N utes-UFRJ, Rio de Janeiro, RJ, Brasil. verahfs@yahoo.com.br

*** Professor do Laboratório de Vídeo Educativo do N utes-UFRJ, Rio de Janeiro, RJ, Brasil. luizrezende.ufrj@gmail.com 
saúde col etiva, notadamente no que se refere à contracepção e às práticas reprodutivas. U m investimento vem ocorrendo na noção de que uma maior responsabilidade paterna terá resultados favoráveis na saúde dos indivíduos. Também na mídia proliferam discursos os mais diversos - e por vezes polêmicos sobre 0 assunto. N o entanto, os estudos sobre a participação do homem no convívio familiar e na esfera reprodutiva são ainda recentes. Alguns autores relatam que a feminilidade e a maternidade foram tradicionalmente priorizadas em relação às questões da masculinidade e da paternidade (Bustamante, 2005a e b; Levandowski; Piccinini, 2006; Lyra et al.,1998; Tronchin; Tsunechiro, 2006).

Este artigo assume tais perspectivas para discutir paternidade, principalmente no que se refere a suas conexões com a saúde reprodutiva, no contexto de recentes transformações que caracterizam a chamada "modernidade tardia". Considerando 0 apelo vindo do campo da saúde coletiva, relacionado à importância de maior conhecimento sobre questões referentes à paternidade, foi realizado um estudo empírico de cunho exploratório, em que analisamos os significados construídos por um grupo de jovens sobre paternidade, em suas relações com sexualidade e saúde reprodutiva. Fundamentamo-nos nas noções foucaultianas sobre construção discursiva do sujeito, sobre relações poder/saber e "tecnologias do eu"; além disso, apoiamo-nos em estudiosos de deslocamentos contemporâneos, como os das transformações nos relacionamentos afetivos e sexuais entre os jovens.

A pesquisa de campo adotou a realização de oficina de videodocumentário como procedimento de geração de dados; assumiu a paternidade como temática para a produção dos documentários - realizados com os jovens - e utilizou todo o processo - desde a elaboração, a gravação, até a finalização - como fonte de dados. A opção de contar com jovens como informantes relaciona-se ao fato de ser a juventude, como apontado por Brandão e H eilborn (2006, p.1422), 0 momento em que a sexualidade e a reprodução se inserem com relevância, sobretudo na esfera da sexualidade, quando são ensaiadas "formas de autonomização em relação aos pais". N ossa identidade com o campo da saúde determinou os contornos conferidos à temática da paternidade.

Iniciamos por caracterizar a paternidade como um construto histórico-cultural, permeado pelas categorias gênero e sexualidade. Em seguida é explicitada a opção por utilizar a vertente documentária da autobiografia como procedimento de geração de dados, para então apresentar os resultados do estudo. Entre outros achados, foram evidenciados discursos tanto dos paradigmas tradicionais como pós-tradicionais, que ajudam a conformar as relações estabelecidas dos sujeitos consigo mesmos e com suas famílias, em relação ao mundo ao redor, e em relação aos seus pais, especialmente no que tange a questões de sexualidade e saúde reprodutiva. 
Sexualidade e gênero como estruturantes nas construções históricas da paternidade

Conforme apontado pela saúde coletiva, padrões nos comportamentos masculinos vêm contribuindo para naturalizar inúmeras questões: a contracepção como assunto feminino; a ausência da figura paterna durante o pré-natal; 0 entendimento de que o cuidado com os filhos é de responsabilidade da mãe ou de uma figura feminina; a delegação das responsabilidades domésticas à figura materna; a concepção de pai como chefe provedor material, justificando sua ausência no processo de desenvolvimento dos filhos, atendimento médico, reunião escolar, etc. Entre outros aspectos, a importância do efetivo envolvimento dos homens nas questões referentes ao exercício da paternidade e a aspectos referentes à saúde reprodutiva deve-se ao fato de eles conviverem "constantemente com a possibilidade de engravidar mulheres com as quais mantêm relacionamento sexual, dado que sua fertilidade é constante e não periódica" (ICD P, 1994, apud Medrado; Lyra, 2000, p. 9).

O investimento nessa temática ganhou maior visibilidade durante a IV Conferência Internacional sobre População e D esenvolvimento, realizada em 1994, no Cairo, sob os auspícios da O N U . As recomendações da Conferência propõem que "esforços especiais devem ser feitos no sentido de enfatizar a coresponsabilidade masculina e promover 0 efetivo envolvimento dos homens com a paternidade responsável e o comportamento sexual e reprodutivo, incluindo-se aí o uso da anticoncepção...". (ICPD, 1994, apud M edrado; Lyra; N ascimento; Galvão, 2000, p.14).

Relacionada a essa questão está a participação mais efetiva dos homens no cotidiano familiar, particularmente no cuidado com os filhos, o que vem sendo comumente chamado de "nova paternidade" (Medrado, 1998). Segundo Lyra et al. (1998, p.14), a compreensão desse modelo de paternidade tem como principal referência M ichael Lamb, para quem o modelo do novo pai é um dos elementos-chave na análise das relações parentais na contemporaneidade. Lamb defende que o pai, assim como a mãe, tem um importante papel no desenvolvimento infantil, não apenas na provisão das necessidades materiais, mas também nas relações de afeto e cuidado (Lamb apud Lyra et al., 1998, p.14). Considerando que homem e mulher são sempre pensados de modo relacional (H eilborn, 1997b), a noção de "novos pais" é um fenômeno que se desenvolve em permanente confronto com o campo do feminino, da divisão social do trabalho e da assimetria de poder. Para Elisabeth Badinter (1992), o perfil do "novo pai" esboça-se a partir de um homem procedente das camadas médias ou altas, beneficiado por uma formação mais elevada que a média, e possuidor de renda. 
A definição do "novo pai" relaciona-se a uma nova configuração da família, deflagrada recentemente diante da crescente inserção da mulher no mercado de trabal ho e da multiplicação das separações conjugais, (D evreux, 2006; G omes; Resende, 2004; Lyra et al., 1998). Responsáveis também pela provisão material do lar, as mulheres passaram a dispensar menos tempo ao cuidado com os filhos, obrigando os homens a dividirem essa tarefa. Para Fonseca (2004, p.17), tais mudanças colocam o homem diante de um sentido de ambivalência em relação ao lugar que deve ocupar, pois o deslocam do seu tradicional papel de provedor,. G omes e Rezende (2004) consideram que essa ruptura gera modos alternativos: o "novo pai" não se ancora mais no poder econômico, fazendo emergir uma nova organização familiar de casais de dupla renda ou dupla carreira.

Levando em conta variáveis como as culturais e as de classe social, observamos o papel do homem nas camadas populares. N esse contexto, verifica-se, por exemplo, que é em torno da ordenação simbólica da família que se estrutura a divisão do trabalho entre os sexos, prevalecendo o grupo sobre o indivíduo na constituição da identidade social das pessoas (H eilborn; Gouveia, 1999). Essa perspectiva ganha maior visibilidade quando confrontada com o "modo individualizante" do modelo cultural vigente entre os segmentos de camadas médias na sociedade brasileira, que tem no indivíduo, na sociabilidade e na ocupação o eixo de estruturação dos sujeitos sociais (H eilborn, 1997a).

\section{0 enunciado de um discurso específico: oficina de vídeo e a produção de narrativas de si}

Supomos que a realização de documentários seja uma atividade capaz de romper, de algum modo, com o campo de silêncios que marca os discursos de jovens sobre questões como as que concernem à paternidade, e propor novos conteúdos: seja por meio do exercício de uma escuta da alteridade, seja por meio de uma outra possibilidade narrativa, mais aberta ao potencial criativo dos jovens. N essas experiências, assumimos que os vídeos não são constituídos das verdades das vidas particulares que lá estão. Se há alguma verdade, essa só pode ser a que trata do "jogo" pelo qual cada um escolheu para se narrar, para dizer de si (Foucault, 1994; Giddens, 2002; Larrosa, 1994).

Tal perspectiva nos permite olhar para a realização dos documentários não só como uma prática que expõe uma dimensão particular do sujeito narrador (seja ela expressa na primeira ou na terceira pessoa), mas também como uma linguagem que é capaz de expor os seus próprios mecanismos de inscrição histórico-discursivos. M ecanismos estes que, além de expor a dimensão subjetiva de um indivíduo, são, ao mesmo tempo, constitutivos desse próprio saber queéo documentário. Por esse motivo, deve-se reconhecer, como D a-Rin (1995) 
sugere, ao citar o pesquisador norte-americano de cinema Bill $\mathrm{N}$ ichols, que 0 documentário se constrói e se reconstrói imerso em uma diversidade de agentes discursivos e não discursivos. N ão tem, portanto, existência como um "objeto-natural" e deve ser compreendido em sua dispersão (Foucault, 2007).

No documentário autobiográfico, a narrativa ocorre na primeira pessoa, e 0 particular determina o geral. As histórias são heterogêneas, múltiplas e pessoais. Trata-se de uma forma específica de relacionar-se com o mundo, onde supomos encontrar um dado campo de expressão, subjetivação e significação. Diferente da produção de um telejornal, por exemplo, a realização de vídeos autobiográficos precisa estabelecer-se no tempo, dado o caráter não objetivo de sua construção (Silva, 2004), ou seja, não existe um modelo de produção consolidado ao qual se possa referir. É preciso experimentar.

A partir dos anos de 1960, várias inovações atravessaram a trajetória do documentário, um gênero que antes era praticamente sinônimo de jornalismo, levando ao desenvolvimento de um tipo de filme que centraliza na figura do próprio documentarista a sua organização temática e formal. Enquanto o modelo clássico busca informações sobre um "outro", tais filmes, denominados autorreflexivos, trabalham a questão da autorreferência (Silva, 2004, p.17). Essa perspectiva do documentário coincide com o período dos movimentos sociais da década de sessenta, marco da modernidade tardia (H all, 2004, p.44), aproximando-se das discussões da pós-modernidade postas por Giddens (2002) em termos de reflexividade e autoidentidade. Pode-se ainda observá-la em termos de confissão ou de técnicas de mediação da relação do sujeito consigo mesmo (Foucault, 1994).

A partir dessa compreensão do documentário, propusemos uma prática onde o locus do conhecimento estava centrado na experiência e não em um conhecimento prévio a ser ensinado. A oficina ${ }^{1}$ foi realizada nas dependências de um Laboratório de Vídeo Educativo de uma universidade pública, com oito jovens matriculados no Ensino M édio, procedentes de diferentes escolas públicas do Rio de Janeiro. N essa oficina foram produzidos vídeos, construídos nas bases do documentário autobiográfico. 0 grupo de jovens foi constituído a partir de uma instância de ensino não formal, uma escola de audiovisual vinculada a uma $\mathrm{O} \mathrm{N} \mathrm{G}^{2}$, frequentada por jovens das classes populares da região metropoli-

1. No estudo maior, do qual este artigo constitui um recorte, foram realizadas duas oficinas, em momentos distintos (primeiro e segundo semestres de 2007), com grupos de jovens também distintos. Em ambas as oficinas foram produzidos documentários pelos jovens - na primeira, um telejornal e, na segunda, um documentário autobiográfico.

2. A escola divide-se em dois núcleos de ensino: um no município do Rio de Janeiro e outro no município de São Gonçalo, ambos na região metropolitana da cidade do Rio de Janeiro, nos quais o primeiro autor atuava como professor na época da pesquisa. 
tana do Rio de Janeiro. $\mathrm{N}$ a realização da oficina, de seis horas, todos foram informados do caráter experimental do trabalho, que tomou como referência maior o trabalho intitulado D ouleur exquise, de Sophie Calle (2003). Esse trabalho tem como "regra do jogo" a narração de histórias particulares a partir de interações pessoais. $\mathrm{N}$ ele, diferentes situações de vida são contadas, ou melhor, trocadas, tendo como ponto de partida a exposição de uma experiência pessoal vivida pela própria autora ${ }^{3}$. Assim, os vídeos consistiram em narrações particulares de histórias sobre questões estabelecidas entre os jovens e a ideia que faziam do "ser" paterno. A conversa girou em torno do que poderíamos considerar "jogos de verdades" (Foucault, 1994). As orientações centraram-se na prática audiovisual, não cabendo qualquer tipo de palestra sobre a temática da pesquisa. D o mesmo modo, esclarecemos que a temática escolhida estava pautada pelas necessidades da pesquisa, podendo os jovens fazer uso do mesmo dispositivo de produção para investigar outras temáticas em outras situações, se assim desejassem. Ante a temática (im)posta, os jovens tinham liberdade para abordá-la do modo que quisessem.

A partir das discussões prévias sobre o tema, propusemos aos jovens que escolhessem (por afinidade) um outro participante e narrassem entre si histórias particulares sobre 0 assunto . Visando descaracterizar a ideia de entrevista, usamos termos como conversa, troca ou negociação entre as partes. A câmera de vídeo foi operada por eles mesmos, o tempo de conversa de cada dupla foi livre e a ordem das gravações determinada pelos participantes. D esse modo, foram gravados oito vídeos de aproximadamente dois minutos cada. Após as gravações, o material bruto foi exibido ao grupo, gerando um forte debate entre os jovens, tanto do ponto de vista da temática quanto das possibilidades estéticas de existência do vídeo como algo publicável ${ }^{4}$.

Era a subjetividade de cada um que estava em jogo no dispositivo adotado para 0 vídeo. Cabe ressaltar que todos optaram por falar dos seus próprios pais. Os depoimentos foram os mais variados: alguns trataram de conflitos, outros de incertezas; alguns refletiram, julgaram, outros não, e assim por diante. Tal variação, a nosso ver, deveu-se a uma espécie de tradução que cada um fez para o termo "questionamento" (usado pelo pesquisador ao propor o exercício). Essas variadas formas de entendimento definem o conjunto do que foi dito por

3. O resultado dessa proposta apresenta-se na forma de um livro-documentário - espécie de dispositivo que, sob uma determinada visão mais contemporânea, vem sendo chamado de "documentário expandido" (Lins, 2007).

4. Cabe notar que dois participantes, um menino e uma menina, não quiseram ter seus vídeos exibidos para todo o grupo, por considerarem os seus depoimentos muito particulares e não amadurecidos o suficiente para tal exposição. $\mathrm{N}$ ão houve restrições, no entanto, quanto aos mesmos vídeos serem usados como material de análise da pesquisa. 
cada um, e também o que não foi dito. Assim, falas como: Tenho vários proble mas com o meu pai (Bernardo) ${ }^{5}$, U m dos principais problemas que eu sempre tive com o meu pai (Caetano), U ma coisa que me aflige na relação com o meu pai (C arlinhos), entre outras, foram usadas para dar início aos depoimentos.

Em meio a problemas, aflições e dores, cada um foi dando forma a sua história particular ou, pelo menos, ao que conseguiu contar delas. Sob uma determinada visão, esse conjunto de ditos e não ditos pertence à produção do discurso, que por sua vez é regulada e controlada por procedimentos que têm justamente a função de determinar o que pode ou não ser dito em um determinado lugar, dominando assim o seu acontecimento (Foucault, 2006). Aqui, destacamos um ponto da obra de Foucault que orientou a análise dos dados, sobretudo se considerarmos o método que adotamos, no qual os sujeitos da pesquisa se narram por meio da produção de vídeos. Trata-se das "tecnologias do eu", conceito que dá sustentação aos estudos do filósofo sobre os diferentes modos de construção da relação do sujeito consigo mesmo. As tecnologias do eu foram definidas por Foucault como procedimentos e técnicas que:

\begin{abstract}
permitem aosindivíduos efetuarem, sozinhos ou com a ajuda de outros, um certo número de operações sobre seus corpose suas almas, seus pensamentos, suas condutas, seus modos de ser; detransformarem-se a fim deaten der um certo estado de felicidade, depureza, de sabedoria, de perfeição ou de imorta lidade(Foucault, 1994, p. 783-813)6.
\end{abstract}

Com esse estudo, Foucault estava se propondo a fazer uma "história da organização do saber" tanto no que se referia à "dominação" quanto no que se referia ao "si", tendo em vista "esboçar uma história das diferentes maneiras nas quais os homens, em nossa cultura, elaboram um saber sobre eles mesmos: a economia, a biologia, a psiquiatria, a medicina e a criminologia". 0 jogo não está em analisar o que de fato existe nesses saberes, mas, sim, o que eles representam no interior daquilo que Foucault chama de "jogo de verdade", visto como uma técnica específica dos sujeitos para conterem em si aquilo que são (idem, 1994, p. 783-813).

Tomando a paternidade como exemplo de um desses saberes, a perspectiva mencionada desloca-nos da necessidade de discuti-la tão somente a partir dos critérios da ciência formal, para nos mostrar por qual tipo de gestão dos indivíduos, no interior e no exterior dessas práticas, o discurso da paternidade se tornou- possível; qual a tecnologia de si ou o "jogo de verdade" que compreen-

5. O s nomes dos jovens aqui utilizados são fictícios.

6. Traduzido a partir de Foucault, Michel. Dits et ecrits. Paris: Gallimard, 1994, p. 783-813, v. 4, por Wanderson Flor do N ascimento e Karla N eves. 
de o pai a que cada indivíduo se refere. $N$ essa perspectiva, o que se busca com a análise dos dados não é a manifestação de um sujeito ou a expressão de algo que teria seu estado puro, mas o lugar de sua dispersão e as diferentes posições, no tempo e no espaço, assumidas por eles na extensa rede de relações de poder que é o discurso.

\section{Histórias organizadas e dispersas em múltiplos discursos}

Um dos jovens, Fred, começou o seu depoimento com pois é, dores e questionamentos são muitos, tá? Eu não sei qual que eu poderia começar, e percorreu a gravação elencando histórias das quais descrevemos algumas. Um fato curioso, porém, ocorreu após todos terem terminado os seus depoimentos e reunirmo-nos de volta na sala para assistir aos vídeos: Fred toma a palavra para dizer que se soubesse que era para falar do pai não teria aceitado o convite. Cabe notar que, ao definirmos as regras de gravação do vídeo (o dispositivo), ficou claro para todos que havia a possibilidade de não falar do tema, desde que os motivos fossem ditos ao companheiro. H avia também a possibilidade de não participar. $M$ as, se a temática não era bem-vinda, por que então ele permaneceu catorze minutos diante da câmera? As respostas podem ser muitas, mas supomos haver, tanto no depoimento de Fred quanto nos dos outros jovens, sentidos que os impelem à fala, imanentes ao dispositivo do documentário autobiográfico, que envolvem desde a possibilidade contemporânea de "estar" no vídeo até as seculares técnicas de se autoexaminar, de se confessar (Foucault, 1988, 1994; Giddens, 1993, 2002; Souza, 1994).

0 primeiro desses sentidos parece girar em torno de uma vontade de verdade: não uma dada verdade, que faria referência ao fato que está sendo contado, mas uma verdade que os ajudaria a compreender aquilo que eles próprios são, aquilo que os constitui como pessoas (Foucault, 1994). Essa é uma técnica que pode e deve ser vista como um instrumento positivo na constituição de novos sujeitos. O utro sentido é o que se refere à ideia da confissão cristã, tal como estudada por Foucault, na qual se destacam dois importantes elementos: a renúncia do sujeito e a técnica da verbalização. De acordo com o autor, "0 indivíduo, pela verbalização constante de seus pensamentos e a obediência da qual dá testemunho a seu mestre, mostra que renuncia à sua vontade e a si mesmo" (idem, 1994, p. 783-813). Ainda segundo Foucault, destacamos um terceiro sentido, que se instala a partir do segundo e se refere à sexualidade e às proibições que pesam sobre ela (idem, 1994).

No campo da repressão, cabe ressaltar alguns aspectos que dizem respeito aos posicionamentos de gênero. $\mathrm{N}$ a situação em que nos encontrávamos meninos e meninas mediados por um pesquisador -, observamos que o lugar 
da fala "transgressora" ficou restrito ao domínio do masculino. Embora os estudiosos da cultura apontem para situações atuais de diferentes "posições do sujeito" (H all, 2004), ainda é muito presente o vínculo com a tradição no que tange às relações entre os sexos. Para H eilborn e Gouveia (1999), uma forte ênfase no controle da conduta sexual da mulher caracteriza a lógica moral exercida nas camadas populares brasileiras. Esse controle, exercido pelo grupo familiar e pelas redes de vizinhança, também estabelecem um quadro de oposição entre mulher de farra e mulher de família (Bozon e H eilborn, 1996). N ão que as meninas não se pronunciassem, mas mostraram-se sempre mais comedidas e racionais em suas falas.

Tendo em vista que um discurso (o da paternidade, neste caso) pode ser definido como um conjunto de enunciados que se apoiam em uma formação discursiva (Fischer, 1997), tomamos a própria oficina como um dos enunciados que dão forma ao discurso em questão. Cabe notar, entretanto, que, se a oficina é um dos enunciados do discurso, isto ocorre porque, em alguma medi$\mathrm{da}$, a matriz de sentidos que determina e regula quais enunciados devem pertencer ou não ao conjunto de enunciados de tal discurso não interditou em suas regras o enunciado da oficina como pertencente ao discurso da paternidade. $\mathrm{O}$ u seja, a própria oficina (como enunciado pertencente ao conjunto do discurso em questão) é constitutiva desse discurso (específico) sobre paternidades, que estamos buscando analisar. Assim, supomos que, da mesma forma que a matriz de sentidos do discurso assume a oficina como um possível enunciado,tudo o mais que a ele (discurso) se refere é parte do conjunto de enunciados que o constrói - por isso, discurso específico; por isso, e ao mesmo tempo, a ideia de dispersão (Foucault, 2007, p. 43). O s enunciados, as coisas ditas - mas que não se confundem com meras frases, imagens ou proposições estão sempre povoados de outros enunciados, estão sempre em correlação com outras formações.

Em relação a essa função-enunciado, que se apóia em conjuntos de signos, o que nos parece fundamental observar é que ela está caracterizada por quatro elementos básicos: um "referencial" (ou princípio de diferenciação); um "sujeito" (ou uma posição ocupada por alguém); um "campo associado" (no sentido da coexistência com outros enunciados); e uma "materialidade" (vista não apenas como o suporte da articulação, mas como um status, que inclui materiais de produção e de reprodução, relacionamentos, etc.). (idem, p.130) .Com isso, identificamos como campo associado da oficina outros enunciados que supomos ser o próprio grupo de jovens, o grupo familiar ao qual pertencem, a camada socioeconômica popular em que vivem, suas identidades, todos compreendendo o domínio da coexistência entre os diversos enunciados que podem estar presentes no discurso em análise. 0 que os diferencia da categoria 
chamada "referencial" parece ser o lugar que cada um desses elementos ocupa na análise, pois, em alguma medida, referencial pressupõe relação. Assim, 0 que se modifica entre uma categoria e outra é o fato de que, no campo associado, há necessariamente coexistência, enquanto no referencial há somente 0 que Foucault chama de "princípio de diferenciação" (2007, p. 130). Sob essa visão, seria um erro observar a oficina isoladamente, mas sempre considerá-la em relação com outros enunciados. Ela existe porque existem os jovens, e também suas famílias, e seus amigos, e estes pertencem ou não a uma determinada camada social.

Por fim, examinemos a materialidade, entendida como um status, ou as formas concretas como o enunciado aparece. N esse caso, não podemos deixar de observar a própria pessoa do pesquisador, pois a oficina toma forma a partir do convite feito por este aos jovens. As compreensões que eles fazem do pesquisador são inegavelmente um dado que confere materialidade à oficina. $M$ as também a oficina deve ser observada como uma materialidade do enunciado, no sentido das mais diversas oportunidades que ela oferece. 0 mesmo vale para a realização de vídeos e para os próprios vídeos realizados, como objetos. De acordo com Foucault (idem, 2007), cabe observar também, na materialidade do enunciado, as suas possibilidades de reprodução, ou seja, as formas como ela (a materialidade) pode aparecer em outros contextos e épocas. Como exemplo de oportunidade, talvez seja pertinente lembrar a fala de Fred durante a gravação do vídeo:

Eu não entendo como eu sou filho dosmeuspais, nós somostotalmentediferentes. Eu não sei deondeeu suguei osmeusobjetivosde vida, queeu sempretive, osmeussonhos, eu nãosei deondevieram, sei lá. Alguma coisa quando eu era criança meinfluenciou sei lá como, né? Acho que... eu via filmes, assim, desdequeeu era muito pequeno eu via filmes com a minha madrinha, eu vi todas as comédiasromânticasdo mundo, eagora eu sou... eu odeio comédia romântica (risos).

Um pouco adiante, Fred descreve um casal de amigos mais velhos, com doutorado e viagens pelo mundo, e atribui à oportunidade de conviver com esse casal a aquisição dos conhecimentos e pensamentos que tem. N esse sentido, a oficina e a relação (extraclasse) com o pesquisador podem ser vistos como uma "possibilidade de uso" ou de "reutilização" (Foucault, 2007, p. 130) concreta dessa ideia de oportunidade.

A mídia é um outro contexto em que a materialidade dos enunciados se reproduz, ou vice-versa. 0 interesse na realização de vídeos tem se mostrado um eco da esfera mediática na vida dos jovens, pois quase todos se relacionam com a câmera a partir dos estereótipos criados pela repetição pedagógica da 
televisão (Fischer, 1997). A evidência disso pode ser vista no controle que cada participante teve sobre o seu momento de fala diante da câmera no início e no final das gravações. Termos como tá gravando?; pode começar?; tá ligada?; foram frequentes antes dos depoimentos, do mesmo modo que conclusões como "é isso aí" (para um suposto telespectador) ou corta, também foram usados ao final. Alguns foram além, mandando beijos e tchau, mostrando uma espécie de domínio ou "vocação para a coisa".

Cada jovem gastou em média dois minutos para contar a sua história. Somente Fred, 17 anos, ultrapassou essa média, levando catorze minutos. Fred voltou até a infância e foi o único que, numa organizada sequência cronológica, veio avançando no tempo, relatando com detalhes as situações que mais lhe pareceram importantes, da adolescência aos dias atuais. As histórias foram selecionadas uma a uma, de modo que, ao terminar a que estava contando, ele refletia em voz alta sobre qual seria a próxima história a ser contada: vamos ver... é porque eu só vou contar as que valem a pena. A ideia de que a vida constitui um todo coerente e organizado, explícito em expressões usadas por Fred, como desde pequeno ou sempre (eu sempre tive objetivo de vida) dá forma ao que Bourdieu considera como tendência do acontecimento a "organizar-se em sequências ordenadas segundo relações inteligíveis" (Bourdieu, 1998, p. 184). Para esse autor, "falar de história de vida é pelo menos pressupor - e isso não é pouco - que a vida é uma história" (1998, p. 183).

D urante a gravação, Fred descreveu situações quase sempre de conflito com o pai: "as lembranças de infância que eu tenho do meu pai é sempre dele me batendo". Diz que o pai nunca foi uma "referência" para ele, pois sempre foi mais cuidado pela mãe e depois, quando a mãe começou a trabalhar, pela avó e pela tia, o que confere com o modelo que compreende que o cuidado com os filhos é uma função feminina. Fred falou muitas vezes do autoritarismo do pai, disse que não tinha respeito por ele, mas medo; que foi muito "reprimido" e por vários motivos; disse que era impedido de questionar qualquer coisa:

ele dizia que eu não podia questionar porque ele não era meu amigo, eleera meu pai. Então essa éuma dasfrasesqueficou muito na minha cabeça. É uma coisa muito louca, assim, eu não sou seu amigo, sou seu pai, comosefossem coi sascompletamentedi ferentes.

Se a perspectiva do "novo pai" não chega a ser uma evidência de revisão da dominação masculina, como observa D evreux (2006), no âmbito dos depoimentos aqui presentes, ela ao menos parece servir para forjar um imaginário de outras formas possíveis de paternidade.

Fred falou ainda de sua adolescência, do seu ingresso aos treze anos em uma grande escola pública que, segundo ele, provocou um choque muito grande 
porque tudo era caótico. Foi lá que ele conheceu pessoas com experiência em luta política, que o inspiraram a ser mais questionador: eu fiz isso muito pela escola, e eu levei isso para a minha vida. Então em casa eu comecei a me impor e querer discutir as coisas, e foi a partir daí que o meu pai parou de me bater e passou a me ouvir mais, mas mesmo assim nunca me dando razão. Vemos que o papel da escola como um lugar de relações sociais entre os jovens ganha concretude nesta fala de Fred. 0 conflito mais recente que teve com o pai levou Fred a sair de casa. D entre os motivos da briga, ele destaca a descoberta na internet de uma situação de infidelidade sexual do pai em relação à mãe.

C abe aqui uma observação mais atenta ao discurso da sexualidade, tal como posto por Foucault (1988), quando trata da questão dos dispositivos da sexualidade e da aliança no contexto familiar. Para 0 autor, a fixação desses dispositivos, sob a forma da família, permite compreender, por exemplo, "que a família tenha se tornado, a partir do século XVIII, lugar obrigatório de afetos, de sentimentos, de amor; que a sexualidade tenha, como ponto privilegiado de eclosão, a família; que por esta razão, ela nasça 'incestuosa'" (Foucault, 1988, p.103). Segundo ele, admite-se que as relações do sexo tenham dado lugar ao dispositivo da aliança por meio da instituição de um sistema de matrimônio, de desenvolvimento dos parentescos, de transmissão dos nomes e dos bens, cujos objetivos principais são a reprodução da trama de relações e a manutenção da lei que as rege. Argumenta que os mecanismos de arrependimento, como a prática da penitência e do exame de consciência, perderam importância à medida que os processos econômicos e políticos da modernidade deixaram de usá-los como suporte. Em troca, o dispositivo da sexualidade, que se instalou historicamente a partir do dispositivo da aliança, articula-se aos parceiros sexuais de modo completamente diferente, "com técnicas móveis, polimorfas e conjunturais de poder", onde o que é pertinente são as "sensações do corpo, a qualidade dos prazeres, a natureza das impressões, por tênues ou imperceptíveis que sejam" (idem, 1988, p.101). Ao que parece, a atitude de Fred diante do comportamento sexual do pai refere-se à manutenção dos dispositivos de aliança, tal como aponta Foucault. Ele descreve a descoberta da relação entre seu pai e outra mulher como um fato "muito chocante", como se 0 vínculo entre o pai e a mãe devesse se manter sob o status definido pelo sacramento matrimonial (Badinter, 1985; Foucault, 1988).

C abe atentar ainda, aqui, para as contribuições trazidas por Giddens (1993) a esta questão, ao referir-se à exploração das potencialidades do que ele chama de "relacionamento puro" e da "sexualidade plástica". 0 primeiro trata de relacionamentos de igualdade sexual e emocional, "explosivo em suas conotações em relação às formas preexistentes do poder do sexo", e o segundo trata da sexualidade descentralizada, liberta das necessidades de reprodução. Embora 
sua origem remeta às tendências do século XVIII, com a contenção do tamanho das famílias, na atualidade ela se desenvolve a partir da difusão das tecnologias reprodutivas. Para Giddens, "a sexualidade plástica pode ser caracterizada como um traço da personalidade e, desse modo, está intrinsecamente vinculada ao eu" (Giddens, 1993, p.10).

Por tudo isso, e, um pouco mais, que certamente nos fugiu à observação, não seria correto caracterizar a fala de Fred como pertencente a este ou àquele dispositivo ou conceito. Tomamos a liberdade de associar a sua atitude ao dispositivo de aliança descrito por Foucault nunca como tentativa de consolidar os motivos reais de sua fal a; o lugar exato de sua existência. Ao contrário, supomos que a descrição dos estudos citados nos permita apenas constatar parte do extenso e disperso campo que constitui o discurso no qual Fred se inscreve ao construir a sua história. Ao finalizar os seus catorze minutos, Fred teceu considerações sobre o pai como alguém que lhe deu sustento e educação. Poderíamos relacionar essa fala ao modelo do pai provedor, que recusa espaço para trocas afetivas (e tudo o mais que constitui o modelo do "novo pai"), porém, como posto, a constituição dos sujeitos não se dá de modo rígido, unívoco, mas disperso em discursos.

H á ainda alguma coisa a ser dita, Fred comenta com C assiana (sua dupla de gravação): ninguém deve estar mais aguentando, né? $M$ as eu vou falando até você achar que está bom, e finaliza dizendo que se considera mais feminino do que masculino: eu tenho uma feminilidade muito grande. Ele atribui isso ao fato de ter sido criado pela tia e pela avó, além da convivência com a irmã. D iz que isso já Ihe causou grandes problemas durante a vida e que já tentou mudar, mas agora desistiu: o fato de eu ser gay ou não, não interessa a ninguém. N ão sou. E isso também atrapalha muito, porque as meninas acham que eu sou amigo delas. Para Fred, a grande questão talvez esteja mesmo aí. Ele diz ter certeza de que este seu comportamento feminino incomoda o seu pai. Ele o descreve como uma pessoa que namorou muitas moças quando solteiro, que gostava de jogar futebol, atividade que Fred diz odiar: ele (o pai) era 'o cara' do bairro. Por fim, diz: a ideia que ele teria de filho eu também não sou, sabe? E a ideia que ele seria de pai pra mim também não é. $A$ esse respeito, parece relevante trazer 0 que vem sendo observado por vasta literatura (H eilborn; Gouveia, 1999; H eilborn, 1997b), meninos e meninas são confrontados desde a infância com as ideias de masculino e feminino em suas vidas.

Fred foi o único que mapeou várias situações da sua relação com o seu pai. Os outros jovens escolheram uma única história, que para uns representava 0 questionamento mais fundamental a ser dito, e para outros nos pareceu ser apenas o cumprimento formal demais um exercício de vídeo. C aetano eBernardo foram a segunda dupla a gravar. Caetano veio de Recife há dois anos. Sua 
história trata de um pai que tentou impor o seu modo de vida particular às pessoas da sua família, criando com isso um afastamento entre os dois e também entre o pai e sua irmã. $\mathrm{H}$ oje seus pais são separados e ele mora com a mãe. Conta que ele proveu materialmente o lar e, portanto, foi um bom pai, mas como não houve aproximação afetiva entre os dois, eles hoje não se dão muito bem. 0 depoimento de Bernardo, 19 anos (um dos jovens que pediu para não exibir o seu depoimento para o grupo), quase não chegou ao fim. Ele é um rapaz muito calado, fala quase nada e assim permaneceu o tempo todo em que estivemos no laboratório. Em seu depoimento de pouco mais de um minuto, Bernardo contou que tem vários problemas com o pai, mas o maior deles diz respeito a sua sexualidade: ele descobriu que eu era gay, no ano passado. Então foi horrível pra mim e ele logo me colocou no psicólogo, e a gente teve vários problemas, várias brigas, foi 0 ano mais terrível da minha vida.

Ao que tudo indica, o discurso da terapia ainda hoje é visto como forma de integrar sexualmente os indivíduos no sistema familiar. Foucault diz que numa sociedade como a nossa, a família é o foco mais ativo da sexual idade e que são as exigências desta última que mantêm e prolongam a sua existência. Foi a instalação do já mencionado dispositivo da sexual idadeque fez com quea família, a partir do século XVII , assumisse o que ele podia representar de estranho eameaçador em relação ao dispositivo da aliança. Assim, os pais se tornam, na família, os "principais agentes de um dispositivo de sexualidade" que tem apoio, fora dela, nos médicos, nos pedagogos e, posteriormente, nos psiquiatras. $\mathrm{N}$ ela, tais práticas se duplicam, por meio dessa forma de agência, em ações que "psicologizam" ou "psiquiatrizam" as antigas relações de aliança, regradas pela definição do permitido e do proibido, do prescrito e do ilícito. É nesse contexto que surgem personagens como "a esposa frígida" e o "jovem homossexual", vistos como figuras da "aliança desviada" e da "sexualidade anormal" (Foucault, 1988, p.104).

Bernardo conta que o pai era um herói para ele na sua infância, mas que depois do ocorrido os dois não têm mais a mesma relação: ele é muito machista, não aceita de jeito nenhum. Eu tento falar com ele, mas... (não consegue terminar a frase e pede para desligar a câmera). Q uando a imagem volta, ele está mais tranquilo e procura terminar a conversa. $M$ as a dificuldade impõe-se novamente, interrompendo mais uma vez o que estava dizendo. Ele fica em silêncio, toma fôlego, até que, melhor, diz que espera um dia voltar a se entender com 0 pai. E pede para desligar a câmera novamente.

$\mathrm{N}$ a conversa final, após a exibição dos vídeos, houve uma longa discussão sobre a necessidade da figura paterna. A maior parte do grupo aderiu à ideia de que a figura do pai é necessária, no sentido de haver uma presença masculina na criação dos filhos, mesmo não havendo laços consanguíneos. Apenas dois foram contrários a essa perspectiva: Caetano e Fred. Ao tentar entender os 
motivos dos dois, Carlinhos questionou se eles não estariam falando de "gené tica", pois, segundo o seu professor, com o desenvolvimento dos estudos da genética as figuras do pai e da mãe tenderiam a desaparecer no futuro. 0 assunto foi retomado, e o pesquisador perguntou como 0 grupo estava vendo 0 desenvolvimento dessas novas técnicas. Sabrina foi a primeira a falar:

se uma mulher ficar grávida de um cara - assim: ele some evai embora, por exemplo, da quister ofilho ed efoi embora - o pai vai ficar: pô, minha filha teveum filho, ficou abandonada, não sei 0 quê... agora, sevocêfaz uma inseminação artificial, parecequeisso dali émaisnormal, assim, do queo cara quefez ofilho efoi embora, não sei, émeio esquisito, meio estranho.

Indagados se os procedimentos artificiais eram mais justificáveis, ela disse: isso, justifica mais como inseminação do que você ter um filho e ser mãe solteira, assim, porque 0 cara não quis e vai embora. Q uestionados por que um caso era visto como mais problemático que o outro, as respostas foram variadas e ditas ao mesmo tempo. Janaína disse que era uma questão de tabu. Fred disse que ser mãe solteira parece violentar mais os pais que a inseminação artificial. C aetano fala em termos de escol ha e uso: "é porque ali foi uma opção sua e no outro caso fica a ideia do uso: minha filha foi usada e descartada; e na inseminação não, é uma escolha".

Giddens $(1993,2002)$ destaca a escolha como uma marca do universo social pós-tradicional e ressalta que, no âmbito do desenvolvimento das tecnologias de concepção, as possibilidades de escolha garantiram para a sexualidade um caráter plenamente autônomo, no sentido de uma reprodução que pode ocorrer livre da atividade sexual. Tais contribuições iluminam as reflexões postas por Sabrina e pelo grupo quando indicam que o centro da polê mica entre a reprodução artificial e a natural parece mesmo estar nas questões do sexo. Uma sociedade como a nossa prevê relações diretas entre o intercurso sexual e a concepção (Strathern, 1995). Assim, na medida em que o sexo é retirado de cena, ter um filho passa a ser um problema social menor para as famílias de mães solteiras (contexto apresentado pelos jovens). $N$ ão que não se possa falar de sexo, mas é preciso saber como, quando e onde é possível falar dele (Foucault, 1988).

\section{Considerações finais}

Como se observa, com apenas um percentual muito pequeno do vasto universo que temos para analisar foi possível descrever uma diversidade de prováveis fatores, associações e posicionamentos que, somados a outros tantos, dão forma tanto ao discurso que constitui a temática desta pesquisa quanto ao 
lugar da sua dispersão. O bservamos um confronto entre esses paradigmas culturais, tidos como tradicionais e pós-tradicionais (Giddens, 1993, 2002; H all, 2004), quando centramos atenções no modelamento das identidades pessoais dos jovens pesquisados, na construção das relações que se estabelecem entre eles e si mesmos, entre eles e os outros, com o mundo que os cerca, e com os próprios pais ou com o pai de uma maneira mais geral.

Supomos que as condições da chamada pós-modernidade venham, de fato, permitindo o reposicionamento constante das identidades desses jovens, mas, ao mesmo tempo, essas novas e múltiplas identidades e possibilidades precisam conviver, no campo prático da vida social, com antigos modelamentos, com situações onde o dado de incerteza expresso de modo mais explícito na contemporaneidade ainda amedronta determinados setores, instituições e indivíduos com os quais esses jovens precisam lidar diariamente.

Assim, tanto o contexto da escola quanto o da família, dos serviços de saúde e da mídia - que é uma espécie de rescaldo de tudo isso - conformam-se muitas vezes em territórios onde a contestação é a expressão mais pura da coexistência desses domínios culturais. Entretanto, por mais paradoxal que possa parecer, supomos que haja aí, apesar dos evidentes conflitos, uma espécie de convivência pacífica, no sentido de uma aceitação do que poderíamos chamar status da paternidade. 0 que estamos tentando dizer, em síntese, é que esse status da relação com o pai, em que estão presentes com muita força as relações de gênero, sexualidade e saúde, constitui um mesmo discurso sobre a paternidade, mesmo com toda reivindicação às tendências de um novo pai, mais afetivo e amigo. $N$ ão que tivéssemos a expectativa de encontrar sinais de outro discurso totalmente oposto acerca do ser pai, como se se tratasse de um discurso descolado da história, mas pretendíamos observar as suas condições de existência na atualidade. Sob esse aspecto, sim, podemos dizer que muita coisa mudou; que o discurso da paternidade não é mais o mesmo discurso produzido em séculos anteriores. Porém, seus aspectos de transformação são sempre muito sutis, dispersos em um número cada vez maior de discursos trazidos às vezes por domínios aparentemente insignificantes, como os próprios atos de contestação descritos pelos jovens durante a pesquisa em relação a seus pais. Estes atos podem ser entendidos como reforçadores do discurso tido como tradicional, mas, dependendo do olhar, também podem ser entendidos como atos que vão, sutil e lentamente, reposicionando este mesmo discurso, de modo que ele próprio não seja nunca o mesmo.

Entretanto, a descrição de práticas cotidianas definidas a partir de uma distinção entre modelos tradicionais e não tradicionais mostrou-se muito presente nas falas dos jovens, da mesma forma que também se tem evidenciado nas falas de sujeitos de outras pesquisas, como professores, profissionais da 
saúde, etc. Assim, embora uma determinada reflexão nos mostre que o discurso contemporâneo da paternidade se constrói a partir da coexistência (pacífica) entre os domínios das culturas tradicionais e não tradicionais de paternidade, parece que no âmbito das práticas cotidianas esses modelos não convivem de modo tão pacífico. Supomos que seja, então, a partir de outros discursos, com os quais o da paternidade interage, que as falas dos jovens sejam produzidas, descrevendo cotidianos cindidos entre tradição e não tradição.

Como dito, é solicitado algo mais amplo que a objetividade informativa para devolver aos jovens o exercício da cidadania e o acesso às oportunidades de desenvolvimento e de aprendizagem. Considerando que os esforços na trajetória da educação e da promoção em saúde são marcados pela inclusão da participação popular nos seus campos de atuação, não poderíamos deixar de mencionar a importância da relação que tais esforços estabelecem com as questões versadas em torno desses processos que chamamos de cidadania. Como tão bem ressalta Thurler (2006, p. 698):

a passagem deum exercício patriarcal paraum exercício contemporâneo e cidadão da paternidadenão é, certamente, processo simples. U ma das propriedades-chavedas relaçõessociais desexo/ gênero éa transversalidade, significan do quesualógicatransbordapor todaa sociedade, articulando camposcomo trabalho produtivo ereprodutivo, trabalho profissional efamília, políticae trabalho. Assim, as questõesda paternidade- patriarcal ou cidadã, arbitráriaou solidária- não secolocam isoladamente.

\section{Referências bibliográficas}

BAD IN TER, E. U m amor conquistado: o mito do amor materno. Tradução de Waltensir Dutra. Rio deJ aneiro: N ova Fronteira, 1985.

BADINTER, E. XY: sobrea identidade masculina. Tradução deM aria I gnez D uqueEstrada. Rio deJ aneiro: N ova F ronteira, 1992. 266 p.

BO U RD IEU , P. A ilusão biográfica. In: FERREIRA, M . deM .; AM AD O , J. (O rg.). U sose abusosda história oral. Rio de Janeiro: Fundação G etúlio Vargas, 1998.

BOURDIEU , P. A dominação masculina. Tradução deM aria H elena Kuhner. 2 ed. Rio de Janeiro: Bertrand Brasil, 2002.

BOZO N , M .; H EILBO RN , M . L. Les caresses et les mots: initiations amoureusesà R io de Janeiro et à Paris. Terrain, Paris, n. 27, p. 37-58, sept. 1996.

BRAN D ÃO , E. R.; HEILBO RN , M . L. Sexualidadeegravidez na adolescência entrejovens de camadas médias do Rio de Janeiro, Brasil. CadernosdeSaúdePública, v. 22, n. 7, p. 14211430, 2006. 
BU STAM ANTE, V. Ser pai no subúrbio ferroviário de Salvador: um estudo de caso com homens decamadas populares. Psicologia Estudantil, M aringá, v. 10, n. 3, 2005 a.

BU STAM ANTE, V. Participação paterna no cuidado de crianças pequenas: um estudo etnográfico com famílias de camadas populares. CadernosdeSaúdePública, Rio deJaneiro, v. 21, n. 6, 2005b.

CALLE, S. D ouleur exquise Paris: ActesSud, 2003.

D A-RIN , S. Espelho partido: tradição etransformação do documentário cinematográfico. 1995. D issertação. (M estrado) - Programa de Pós G raduação em Comunicação, Escola de Comunicação, U niversidadeF ederal do Rio de Janeiro, Rio de Janeiro, 1995.

DEVREUX, Anne-M arie. A paternidadena França: entreigualização dos direitos parentaise lutas ligadas às relações sociais desexo. Soci edadeeEstado, Braślia, v. 21, n. 3, 2006.

FISCH ER, R. M . B.. O estatuto pedagógico da mídia : questões de análise. Educação \& Realidade, Porto Alegre: v. 22, n. 2, p. 59-80, jul./dez., 1997.

FO N SECA, C. A certeza que pariu a dúvida: paternidade e DN A. Revista Estudos Femininos, Florianópolis, v. 12, n.2, maio/ago, 2004.

FO U CAU LT, M .. H istória da sexualidadel : a vontade desaber. Tradução deM ariaT hereza da Costa Albuquerquee J. A. G uilhon Albuquerque. Rio deJ aneiro: G raal, 1988.

FO U CAU LT, M . D itset écrits, Paris: G allimard, 1994. p. 783-813. v. 4.

FO U CAULT, M. A ordem do discurso. 14. ed. São Paulo: Loyola, 2006.

FO U C AU LT, M . Arqueol ogia do saber. Tradução de Luiz Felipe Baeta N eves. 7 ed. Rio de Janeiro: Forense, 2007.

GID DEN S, A. A transformação da intimidade. Sexualidade, amor eerotismo nas soci edades modernas. São Paulo: EditoraU nesp, 1993.

GID D EN S, A.. M odernidadeeidentidade Tradução dePlínio D entzien. Rio deJ aneiro: Jorge Zahar, 2002.

GOM ES, A. J. daS.; RESEN DE, V. daR. 0 pai presente: 0 desvelar da paternidadeem uma família contemporânea. Psicol ogi a: Teoria ePesquisa, Braślia, v. 20, n. 2, 2004.

H ALL, S. A identidade cultural na pós modernidade. Tradução de Tomaz Tadeu da Silva e Guaracira Lopes Louro. 9. ed. Rio deJ aneiro: D P\& A, 2004.

H EILBO RN , M . L. $O$ traçado da vida: gênero eidadeem dois bairros popularesno Rio de Janeiro. In: M AD EIRA, F.; M UÑ O Z-VARGAS, M . (O rg.). Q uem mandou nascer mulher: gênero einfânciano Brasil. Rio de Janeiro: Rosa dosTempos: U nicef, 1997a. p. 291-392.

H EILBO RN , M . L. G ênero, sexualidade e saúde. In: U erj. (O rg.). Saúde, sexualidade e reprodução - compartilhando responsabilidades. Rio deJaneiro: Eduerj, 1997b. p. 101-110.

HEILBO RN , M . L.; G O UVEIA, P. F. M arido étudo igual: mulheres popularesesexualidade no contexto da Aids. In: PARKER, R.; BARBO SA, R. M . (O rg.). Sexualidades pel 0 avesso. Direitos, identidadesepoder, IM S/U ERJ. Rio deJaneiro: Editora34, 1999. p. 175-198. 
LARROSA, J. Tecnologias do eu e educação. In: SILVA, T. T. (0 rg.). 0 sujei to da educação: estudosfoucaultianos. Petrópolis, Rio de Janeiro: Vozes, 1994.

LEVAN D OW SKI, D. C.; PICCIN IN I, C. A. Expectativas e sentimentos em relação à paternidadeentreadolescentes eadultos. Psicologia: Teoria ePesquisa, Brasília, v. 22, n.1, 2006.

LIN S, C. L. 0 documentário expandido deM aurício D ias eWalter Riedweg. D ossier eletrônico VídeoB rasil. São Paulo: Associação VídeoBrasil, 2007.

LYRA, J. Paternidade adolescente: da investigação à intervenção. In: ARILH A, M .; U N BEH AU M , S.; M ED RAD O , B. (O rg.). H omensemasculinidades: outras palavras. São Paulo: ECO S/Ed. 34, 1988. p. 185-214,.

LYRA, J.; M ED RADO , B.; AD RIÃO ,K.; LIM A, J.; M ELO , L.; SILVA, A.; VIEIRA, N . Papai: uma experiência de ensino, pesquisa e extensão. Cadernos da Extensão, Recife, ano 1, n. 1, p. 57-66, dez., 1998.

M ED RAD O , B.; LYRA, J. Paternidadena adolescência: paraalém daprevenção. BVS- Biblioteca Virtual em Saúde - Adolec., 2000. D isponível em: «ttp://www.adolec.br/bvs/adolec/P/ textocompleto/pfpaternida.htm>. Acesso em: 29 dez. 2009.

MEDRAD O, B.; LYRA, J .; N ASCIM EN TO , P.; GALVÃO , K. H omens, por quê? Uma leitura da masculinidadea partir de um enfoque degênero. Perspectivasem Saúdee D ireitos Reprodutivos, São Paulo/SP, v. 3, p. 12-16, 2000.

M ED RAD O , B. H omens na arena do cuidado infantil: imagens veiculadas pela mídia. In: ARILH A, M .; RID ENTI, S.; M EDRAD O , B. (O rg.) - H omensemasculinidades outraspalavras. São Paulo: ECOS, 1998 p. 145-162.

SILVA, R. A. S.; SO ARES, R. Juventude, escola emídia. In: LOURO , G. L.; N ECKEL, J. F.; GO ELLN ER, S.V. (O rg.). Corpo, gênero esexualidade: um debatecontemporâneo na educação. Petrópolis: Vozes, 2003.

SILVA, P. R. da. D ocumentários performáticos: a incorporação do autor como inscrição da subjetividade. 2004. D issertação. (M estrado) - Programa dePós-G raduação em Comunicação, Escola deC omunicação, U niversidadeF ederal do Rio de J aneiro, 2004.

SO UZA, M. W. de. Juventude e os nossos espaços sociais de construção e negociação de sentido. Educação \& Realidade, Porto Alegre, v. 22, n. 2S/97, p. 47-58, 1994.

ST RATH ERN , M . N ecessidade depais, necessidade demães. EstudosFeministas, v. 3, n. 2, p. 303-329, 1995.

TH U RLER, A. L. O utros horizontes para a paternidadebrasileira no século XXI? Sociedadee Estado, Braślia, v. 21, n. 3, 2006.

TRO N C H IN , D .; TSU N ECH IRO, M . A. Cuidar e o conviver com o filho prematuro: a experiência do pai. Revista Latino-Americana deEnfermagem, Ribeirão Preto, v. 14, n. 1, 2006.

Recebido em 04 dejaneiro de2010 eaprovado em 07 dejulho de 2010. 
